archives

of thermodynamics

Vol. 36(2015), No. 3, 61-83

DOI: $10.1515 /$ aoter-2015-0022

\title{
Effect of flue gas recirculation on heat transfer in a supercritical circulating fluidized bed combustor
}

\author{
ARTUR BEASZCZUK ${ }^{1}$ \\ Czestochowa University of Technology, Institute of Advanced Energy \\ Technologies, Dąbrowskiego 73, 42-200 Czestochowa, Poland
}

\begin{abstract}
This paper focuses on assessment of the effect of flue gas recirculation (FGR) on heat transfer behavior in 1296t/h supercritical coal-fired circulating fluidized bed (CFB) combustor. The performance test in supercritical CFB combustor with capacity $966 \mathrm{MW}_{t h}$ was performed with the low level of flue gas recirculation rate $6.9 \%$ into furnace chamber, for $80 \%$ unit load at the bed pressure of $7.7 \mathrm{kPa}$ and the ratio of secondary air to the primary air $S A / P A=0.33$. Heat transfer behavior in a supercritical CFB furnace between the active heat transfer surfaces (membrane wall and superheater) and bed material has been analyzed for Geldart B particle with Sauter mean diameters of 0.219 and $0.246 \mathrm{~mm}$. Bed material used in the heat transfer experiments had particle density of $2700 \mathrm{~kg} / \mathrm{m}^{3}$. A mechanistic heat transfer model based on cluster renewal approach was used in this work. A heat transfer analysis of CFB combustion system with detailed consideration of bed-to-wall heat transfer coefficient distributions along furnace height is investigated. Heat transfer data for FGR test were compared with the data obtained for representative conditions without recycled flue gases back to the furnace through star-up burners.
\end{abstract}

Keywords: Heat transfer coefficient; Cluster renewal approach; Flue gas recirculation; Circulating fluidized bed

\footnotetext{
${ }^{1}$ E-mail: ablaszczuk@is.pcz.czest.pl
} 


\section{Nomenclature}

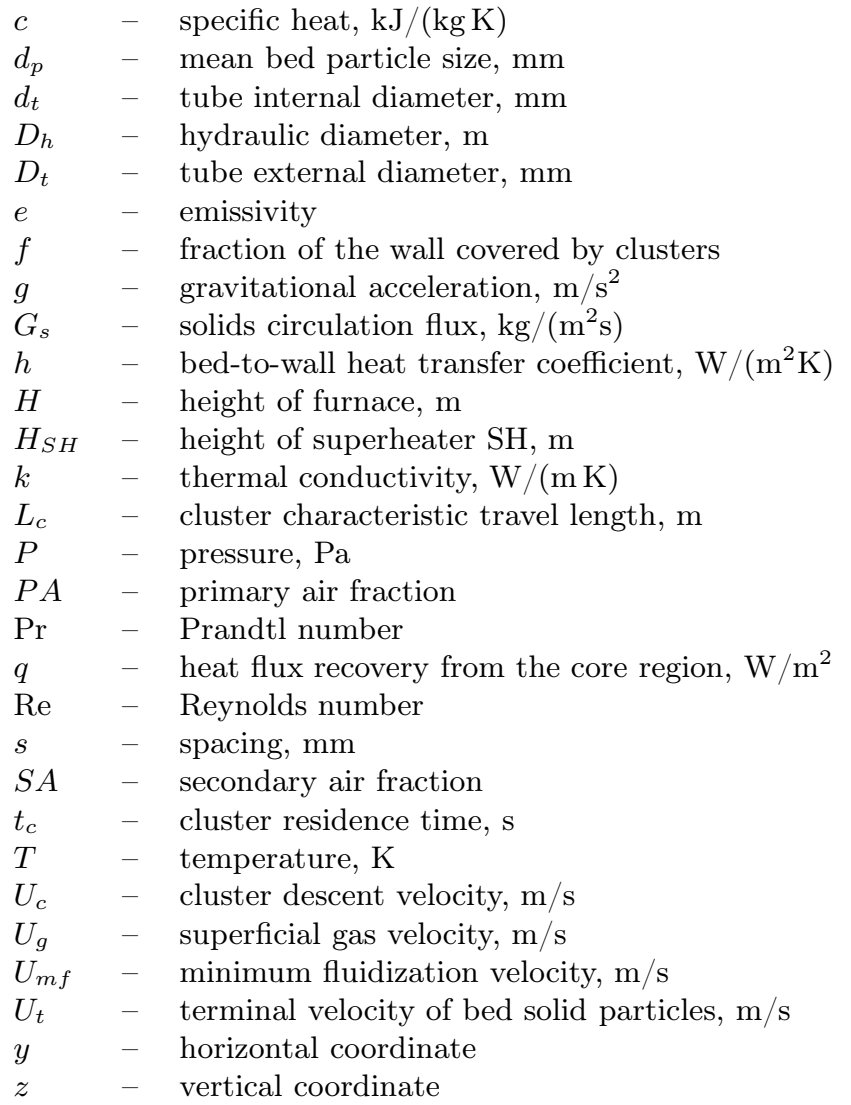

\section{Greek symbols}

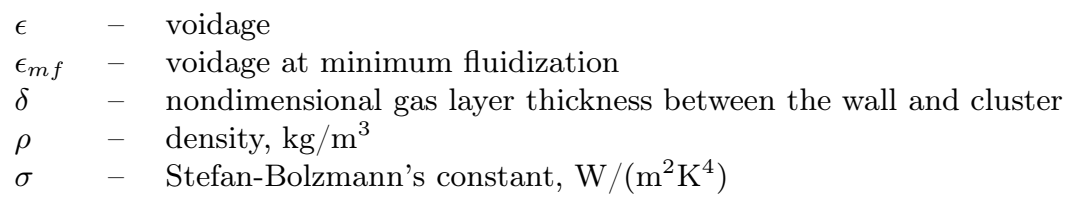

\section{Subscripts}

$$
\begin{array}{lll}
b & - & \text { suspension } \\
c & - & \text { cluster } \\
d & - & \text { dispersed } \\
f & - & \text { fluidization }
\end{array}
$$




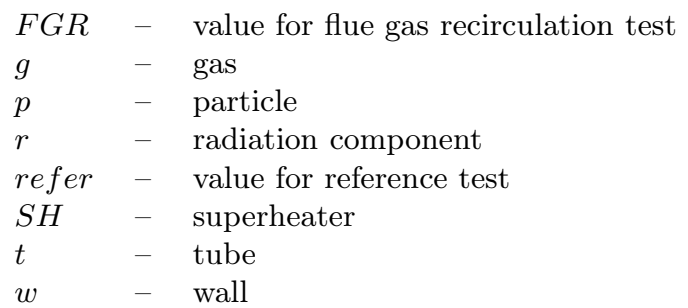

\section{Introduction}

Circulating fluidized bed (CFB) combustion of fossil fuels is one of the technologies used to electricity generation and production of heat. This technology is characterized by fuel flexibility and multi fuel operation, high availability, net efficiency near $45 \%$ (higher steam parameters), low emissions of air pollutions $\left(\mathrm{SO}_{2}\right.$ and $\left.\mathrm{NO}_{x}\right)$ into the atmosphere and also possibility to cut carbon dioxide emissions. Since 1995, CFB units have been actively developing with an increasing capacity of industrial CFB boilers [1-4]. In the modern power generation systems, one way of equalize furnace temperature profiles, both horizontal and vertical profiles, is flue gas recirculation (FGR) [5]. Several alternative possibilities exist to controlling of the reaction temperature in combustors: (i) commonly used external flue gas recirculation [6], (ii) internal flue gas recirculation [7], (iii) burner operation under nonstoichiometric conditions [8]. Moreover, in CFB boilers the flue gas recirculation into combustion chamber affect: (i) reduction of $\mathrm{NO}_{x}$ emissions from combustion process in two ways: lowering peak flame temperatures as well lower the average oxygen content of the oxidant $[9,10]$, (ii) flame stability (i.e., lowering adiabatic flame temperature) [11], (iii) thermal material stability for oxy-fuel combustion technology with oxygen concentration over 25 vol.\% in the oxidant [12], (iii) scale-up and design of heat transfer surfaces for CFB combustors, in particularly a change in the heat transfer distribution between radiative section of furnace chamber and back pass [13]. Combustion process based on flue gas recirculation into the circulating fluidized bed boiler is easy to implement for control of heat transfer conditions inside furnace chamber. Too high furnace temperature is the main problem in maintain the optimum operating conditions in order to reduce greenhouse gas emissions into the atmosphere. Thus, CFB combustion systems need to be carefully designed, and optimized to ensure efficient operation. For this reason, detailed knowledge and experience about the heat transfer mechanisms inside a large-scale furnace chamber 
are major aspects to properly design an effective active heat transfer surface and to achieve desirable high performance in the circulating fluidized bed combustor. Recent research studies have been focused on heat transfer characteristic in the laboratory or pilot scale [14-18], but as far as author knows, there are not studies about how flue gas recirculation influences heat absorption from the bed material to the membrane wall in large-scale CFB unit. This fact is due to measuring difficulties and commercial reasons.

In the current research study, a mechanistic heat transfer model based on cluster renewal approach was used in order to evaluate the contribution of particle convection, gas convection, cluster convection, radiation from cluster dispersed phase to the overall heat transfer coefficient. The model takes into account the effect of fractional of the wall exposed to clusters, gas gap thickness between clusters and the wall, thermal conductivity of the cluster, cluster solid fraction and residence time of the cluster in a CFB unit. To estimate the bed-to-wall heat transfer coefficient, the experimental data from CFB combustor in a large-scale were used. The heat transfer mechanism in a CFB combustor was analysed for two representative conditions at flue gas recirculation into CFB furnace and reference test under normal operating conditions. The percentage contribution of the convection and the radiation heat transfer components were estimated for upper region of furnace chamber, above the secondary air injection, where membrane wall surfaces and radiant superheaters are located.

\section{Mechanistic heat transfer model}

In order to explain the behavior of heat transfer inside CFB furnace and improve fluidized bed design procedures, mechanistic heat transfer model has been proposed. Besides, the correct scale-up of heat transfer surfaces it is important to ensure proper operation, load turndown and optimization of CFB combustors.

In the heat transfer model used the cluster renewal approach simultaneously predicts the hydrodynamics aspect. A major feature of gas-solids flow structure in CFB combustors is a core-annulus flow pattern. The crosssection of furnace chamber is divided into two regions: (i) a dilute core with bed particles transported upwards with an occasional presence of clusters are entrained by the fluidizing gas, (ii) a dense and smaller annulus region or gas-solid boundary layer with clusters flowing down at active heat transfer surface (membrane wall or superheater). Bed particles or clusters, after 


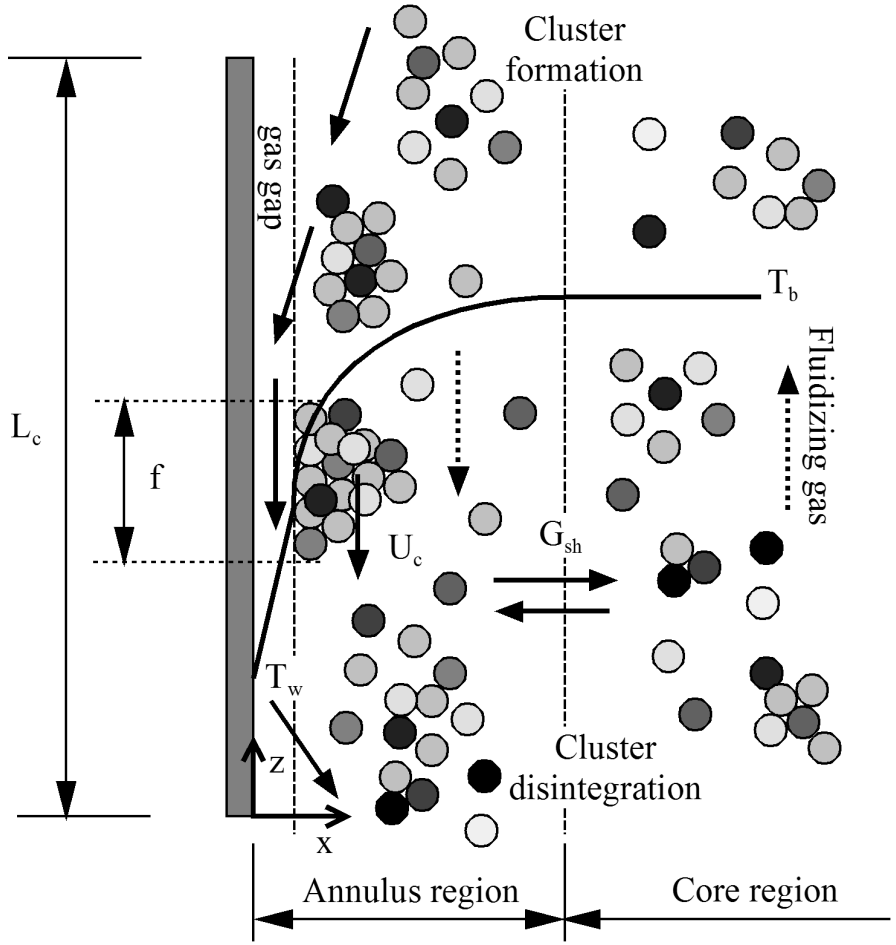

Figure 1: Single cluster formation and gas gap in the vicinity of active heat transfer surface, $\mathrm{G}_{s h}$ is the lateral solid circulation flux in $\mathrm{kg} /\left(\mathrm{m}^{2}\right)$.

traveling a certain distance dissolve or detach themselves from the wall. Then they are re-entrained into the core region and replaced by fresh particles that have the same temperature as the bed inventory. Based on these considerations, the active heat transfer surface comes interchangeably in the contact with clusters and the dispersed phase. In the current heat transfer study, the correlation suggested by Wu et al. [19] for large-scale CFB units was adopted for estimation of cluster characteristic travel length:

$$
L_{c}=0.0178 \rho_{b}^{0.596},
$$

where $\rho_{b}$ is the suspension density in $\mathrm{kg} / \mathrm{m}^{3}$. Time of contact between clusters and the wall (residence time) $t_{c}$ depend upon bed hydrodynamic conditions and it can be estimated in CFB combustors from equation given by Noymer et al. [20]

$$
t_{c}=\frac{L_{c}}{0.75\left(\rho_{p} g d_{p} / \rho_{g}\right)^{0.5}},
$$


where $g$ denotes gravitational acceleration in $\mathrm{m} / \mathrm{s}^{2}, d_{p}$ is mean bed particle size in $\mathrm{m}, \rho_{p}$ and $\rho_{g}$ are particle density and gas density in $\mathrm{kg} / \mathrm{m}^{3}$ respectively.

The heat transfer between the surface and the fluidized bed includes contributions of four mechanisms: (i) particle convection, (ii) gas convection, (iii) radiation from clusters, (iv) and also radiation from dispersed phase. The contribution of these heat transfer mechanisms is considered as disjoint heat transport towards the membrane wall and also the superheater wall in CFB combustor. Thus, the overall heat transfer coefficient between circulating fluidized bed and active heat transfer surface is written as

$$
h=f h_{p}+(1-f) h_{g}+f h_{c r}+(1-f) h_{r d},
$$

where $h_{p}$ denotes particle convection heat transfer coefficient, $h_{g}$ represents gas convection heat transfer coefficient, $h_{c r}$ means radiation heat transfer coefficient for clusters, and $h_{r d}$ is radiation heat transfer coefficient for dispersed phase. In Eq. (3), $f$ denotes the fraction of the wall covered by clusters and is calculated using expression given by Dutta and Basu [21]

$$
f=1-\exp \left[-4300(1-\varepsilon)^{1.39}\left(D_{h} / H\right)^{0.22}\right],
$$

where $D_{h}$ is the hydraulic diameter in $\mathrm{m}, H$ represents the furnace height in $\mathrm{m}$ and $\epsilon$ denotes cross-sectional of bed average voidage. This empirical formula was received on the basis of experimental data from four CFB combustors in large-scale with different equivalent diameter at different levels above the secondary air injection.

A description of the individual heat transfer components is characterized below. The heat transfer by particle convection $h_{p}$ refers to the energy transferred due to continuous particle motion between active heat transfer surface and the core region. The particle convection component in the heat transfer coefficient consists of conductive heat transfer into the clusters and the thermal conduction across the thin gas layer. Thus, the particle convection heat transfer coefficient is estimated using the following relation:

$$
h_{p}=\left(\frac{1}{h_{c}}+\frac{1}{h_{w}}\right)^{-1}=\left[\left(\frac{\delta_{g} d_{p}}{k_{g}}\right)+\left(\frac{\pi}{4} \frac{t_{c}}{k_{c} \rho_{c} c_{c}}\right)^{0.5}\right]^{-1},
$$

where $h_{c}$ denotes time averaged cluster heat transfer coefficient in $\mathrm{W} /\left(\mathrm{m}^{2} \mathrm{~K}\right)$, $h_{w}$ means heat transfer coefficient due to conduction through gas gap in the 
vicinity of the wall in $\mathrm{W} /\left(\mathrm{m}^{2} \mathrm{~K}\right), \delta_{g}$ represents thickness of the gas layer residing between the active heat transfer surface and the clusters in $\mathrm{m}, k_{g}$ and $k_{c}$ are thermal conductivity of the gas and thermal conductivity of clusters in $\mathrm{W} /(\mathrm{mK})$, respectively. In Eq. (5), parameter $\rho_{c}$ represents cluster density in $\mathrm{kg} / \mathrm{m}^{3}$, and $c_{c}$ means specific heat of the clusters in $\mathrm{kJ} /(\mathrm{kg} \mathrm{K})$. Formulas needed to estimate physical and thermal properties of clusters and gas phase can be found in [22,23].

The gas convection heat transfer coefficient becomes significant in fluidized beds at large Archimedes number or low solid concentration. The convection heat transfer from gas phase to the wall is given by the expression

$$
h_{g}=\frac{k_{g} c_{p}}{d_{p} c_{g}}\left(\frac{\rho_{d}}{\rho_{p}}\right)^{0.3}\left(\frac{U_{t}^{2}}{g d_{p}}\right)^{0.21} \operatorname{Pr},
$$

where $U_{t}$ represents terminal velocity of the bed particles in $\mathrm{m} / \mathrm{s}, \rho_{d}$ denotes dispersed phase density in $\mathrm{kg} / \mathrm{m}^{3}, \operatorname{Pr}$ is a Prandtl number, $c_{p}$ and $c_{g}$ are specific heat of particle and specific heat of gas in $\mathrm{kJ} /(\mathrm{kgK})$, respectively. Other denotations in Eq. (7) are explained in the Eq. (5). In above the equation (7), terminal velocity is estimated from the following formula:

$$
U_{t}=\left(\frac{4 d_{p} g\left(\rho_{p}-\rho_{g}\right)}{3 \rho_{g} C_{D}}\right)^{0.5},
$$

where $C_{D}$ represents the drag coefficient and it depends upon the flow regime. In the present study in order to obtain the drag coefficient the intermediate law is used within the particle Reynolds number range of $0.4<$ $\operatorname{Re}_{p}<500$.

Assuming that the cluster free parts of the fast fluidized bed inventory are not solids free, although, a small quantity of particles is dispersed in the up-flowing gas, in this work dispersed phase density is calculated as

$$
\rho_{d}=\rho_{p} Y+\rho_{g}(1-Y),
$$

where $Y$ means the volumetric concentration of bed inventory particles and this parameter has a constant value of $0.001 \%$ as suggested by Basu and Cheng [24].

Similar to the convective heat transfer coefficient, the radiation from the bed to the wall comprised two components: (i) a cluster phase $h_{r c}$ and (ii) a dispersed phase $h_{r d}[25]$. The thermal radiation between the cluster and the wall surface is estimated by considering the cluster and the wall as two 
parallel plates. Thus, the cluster radiation component of the bed-to-wall heat transfer coefficient is estimated using the following equation:

$$
h_{r c}=\frac{\sigma\left(T_{c}^{2}+T_{w}^{2}\right)\left(T_{c}+T_{w}\right)}{\left(1 / e_{c}+1 / e_{w}-1\right)},
$$

where $T_{c}$ represents the temperature of cluster in $\mathrm{K}, T_{w}$ denotes the wall temperature in $\mathrm{K}, \sigma$ is the Stefan-Bolzmann's constant, $e_{w}$ is the emissivity of the heat transfer surface which is the property of the surface. In the current work, the wall emissivity $e_{w}$ is assumed to have a constant value 0.8 and the emissivity of the cluster $e_{c}$ is estimated from correlation given by Grace $[26]$

$$
e_{c}=0.5\left(1+e_{p}\right),
$$

which takes account of inert particle radiation. The particle emissivity of 0.7 is used in the current heat transfer study. The dispersed phase radiation heat transfer coefficient from bed to wall is estimated using the following equation [27]:

$$
h_{r d}=\frac{\sigma\left(T_{b}^{2}+T_{w}^{2}\right)\left(T_{b}+T_{w}\right)}{\left(1 / e_{d}+1 / e_{w}-1\right)},
$$

where $e_{d}$ means the emissivity of dispersed phase, $T_{b}$ denotes bed temperature in $\mathrm{K}$ and other denotations are explained by Eq. (10). A correlation utilized to this investigation for getting effective emissivity of a dispersed phase was estimated based on the Brewster formula

$$
e_{d}=\left[\frac{e_{p}}{\left(1-e_{p}\right) B}\left(\frac{e_{p}}{\left(1-e_{p}\right) B}+2\right)\right]^{0.5}-\frac{e_{p}}{\left(1-e_{p}\right) B} .
$$

using the two-flux method and referring to particle emissivity and backscatter fraction [28]. For isotropic scattering $B=0.5$ is assumed in this heat transfer study.

\section{Performance tests and experimental conditions}

Performance tests were needed to assessment of the effect of flue gas recirculation on heat transfer behavior in a large-scale supercritical CFB facility. The performance tests (i.e., FGR test and reference test) were carried out with a maximum-continuous-rating (MCR) load of $80 \%$ under stable operation conditions. Before each test, the operation conditions of supercritical CFB combustor were stabilized for four hours. The performance tests were 
carried out during a two-day period with each test lasting eight hours. The long time for each test was needed in order to establish the repeatability of experimental results. The experimental conditions referred to this heat transfer study and further for heat transfer characteristic inside furnace chamber are shown in Tab. 1.

Table 1: Experimental conditions.

\begin{tabular}{|l|c|c|c|}
\hline \multicolumn{1}{|c|}{ Parameter } & Unit & FGR test & Reference test \\
\hline \hline Superficial gas velocity, $U_{g}$ & $\mathrm{~m} / \mathrm{s}$ & 4.27 & 3.89 \\
\hline Terminal velocity, $U_{t}$ & $\mathrm{~m} / \mathrm{s}$ & 1.99 & 2.36 \\
\hline Minimum fluidization velocity, $U_{m f}$ & $\mathrm{~m} / \mathrm{s}$ & 0.01643 & 0.02364 \\
\hline Solid circulation flux, $G_{s}$ & $\mathrm{~kg} /\left(\mathrm{m}^{2} \mathrm{~s}\right)$ & 23.7 & 25.6 \\
\hline Particle Reynolds number, $R e_{p}$ & - & 7.57 & 7.92 \\
\hline Particle density, $\rho_{p}$ & $\mathrm{~kg} / \mathrm{m}^{3}$ & 2700 & 2700 \\
\hline Sauter mean particle diameter, $d_{p}$ & $\mathrm{~mm}$ & 0.246 & 0.272 \\
\hline Bed pressure, $p_{b}$ & $\mathrm{kPa}$ & 7.7 & 7.7 \\
\hline Bed height, $H_{b}$ & $\mathrm{~m}$ & 4.87 & 5.26 \\
\hline Bed temperature, $T_{b}$ & $\mathrm{~K}$ & 1126 & 1160 \\
\hline Furnace temperature difference, $\Delta T$ & $\mathrm{~K}$ & 40 & 144 \\
\hline Excess air ration, $\lambda$ & - & 1.22 & 1.21 \\
\hline
\end{tabular}

In the current research study, the performance tests on the supercritical CFB combustor with the capacity of $966\left[\mathrm{MW}_{t h}\right]$ were conducted jointly by Czestochowa University of Technology and Tauron Generation S.A., Lagisza Power Plant (Poland), including some measurements of the pressure and the temperature within the combustion chamber. More information about the CFB combustor can be found in the works $[22,23,25,27,29]$, in which particularly are presented construction data, cross-sectional area, geometry of membrane wall, arrangement of measuring points and also data acquisition system.

In the transport zone of furnace chamber are located main heat transfer surface in the form of membrane wall. Moreover, in the exit region of combustion chamber radiant superheaters are located. The radiant superheaters SH II are constructed in the form of steam tubes panels. The tubes have a $63.5 \mathrm{~mm}$ outside diameter with spacing of $65 \mathrm{~mm}$. More detailed information about the geometry characteristic are given in Tab. 2. 
Table 2: Panel structure for radiant superheaters SH II.

\begin{tabular}{|l|c|c|c|}
\hline \multicolumn{1}{|c|}{ Parameter } & Symbol & Unit & Value \\
\hline \hline Tube external diameter & $D_{t}$ & $\mathrm{~mm}$ & 63.5 \\
\hline Tube internal diameter & $d_{t}$ & $\mathrm{~mm}$ & 42.5 \\
\hline Tube wall thickness & $\delta_{t}$ & $\mathrm{~mm}$ & 10.5 \\
\hline Tube spacing & $s_{t}$ & $\mathrm{~mm}$ & 65 \\
\hline Number of tubes & $n_{t}$ & $\mathrm{~mm}$ & 156 \\
\hline Superheater height & $H_{S H}$ & $\mathrm{~m}$ & 20 \\
\hline
\end{tabular}

In the present study, a cold flue gas without dust was led to the furnace chamber in the slope section through the start-up burners. Injection points of a flue gas into the furnace chamber are located on both sidewalls $(3+3 \mathrm{pcs}$ at the left wall and right wall $)$ and the rear/front wall $(2+2 \mathrm{pcs}$ at front and rear wall), respectively. Properties of that flue gas fed to furnace are listed in Tab. 3.

Table 3: Characteristic parameters of flue gas in the present study.

\begin{tabular}{|l||c|c|c|c|c|c|c|c|}
\hline Parameter & $\mathrm{O}_{2}$ & $\mathrm{CO}_{2}$ & $\mathrm{H}_{2} \mathrm{O}$ & $\mathrm{N}_{2}$ & $V_{F G}$ & $n_{F G}$ & $T_{F G}$ & $\rho_{F G}$ \\
\hline Unit & vol. $\%$ & vol. $\%$ & vol. $\%$ & vol. $\%$ & $\mathrm{~m}_{n}{ }^{3} / \mathrm{s}$ & $\%$ & $\mathrm{~K}$ & $\mathrm{~kg} / \mathrm{m}^{3}$ \\
\hline Value & 3.4 & 17.8 & 12.4 & 66.3 & 20.5 & 6.9 & 395 & 1.314 \\
\hline
\end{tabular}

The recirculation rate, $n_{F G}$, is defined as volumetric flow ratio between the amounts of recirculated flue gas to distinction between a total flue gas products and flue gas recycled back to the furnace chamber, as follows:

$$
n_{F G}=\frac{V_{F G}}{V_{t o t}-V_{F G}}
$$

where $V_{F G}$ denotes the amount of recirculated flue gas into CFB furnace in $\mathrm{m}_{n}^{3} / \mathrm{s}$ and $V_{\text {tot }}$ represents volumetric flow of the total flue gas products in $\mathrm{m}_{n}^{3} / \mathrm{s}$.

The dry flue gas compositions $\left(\mathrm{O}_{2}, \mathrm{CO}_{2}\right.$, and $\left.\mathrm{H}_{2} \mathrm{O}\right)$ were continuously monitored. The main gas analysis system Gasmet ${ }^{T M}$ was located between the flue gas cooler and the cooling tower. The gas analysis system consists of the analytical instrumentation included a analyzer with $\mathrm{ZrO}_{2}$ sensor for $\mathrm{O}_{2}$ measurements, Fourier transform infrared gas analyzer for $\mathrm{CO}_{2}$ and 
$\mathrm{H}_{2} \mathrm{O}$ measurements, sampling probe, heated sampling lines, condenser, two stage particulate filtration and also external pump. Analyzers were zeroed and spanned with standard mixtures at the beginning of each test and also after each measurement session. The flue gas sample was drawn through the probe and pump. A condenser removed any residual moisture and a filter removed the solids particulate so that a constant supply of clean dry flue gases was delivered to analyzers through a flexible and heatable manifold. Reproducibility of the concentration of flue gas components was $<2 \%$ of the measuring range.

\section{Results and discussion}

Some process data used in this work are given in dimensionless scale and normalized by the maximum value of furnace data by reason of confidential commercial information for CFB combustors in large-scale. In the case of Figs. 2, 3, 4 and 5, the lines represent approximation of the experimental data by means of cubic B-spline method using origin software for data analysis [30]. To perform the heat transfer characteristic some process data (i.e. furnace temperature, suspension density) of the coal-fired CFB combustor were used. The bed-to-wall heat transfer coefficient and contribution of heat transfer mechanisms inside furnace chamber were estimated using cluster renewal approach for FGR test and reference test, respectively. The impact of flue gas recirculation on heat flux recovery in a large-scale CFB combustor is investigated.

Figure 2 illustrates vertical temperature profiles in the core region inside CFB furnace at different heights above the air distributor. As expected, it can be seen for the FGR test that there is a quasi-linear furnace temperature profile in opposition to the reference test. Flue gas recirculation affected the hydrodynamic conditions in the slope section of the furnace chamber. The temperature discrepancy in the transport zone of CFB furnace between the reference test and the FGR test was a result of shorter cluster residence time on the active heat transfer surface and also higher cluster descent velocity compared to the FGR test. Moreover, furnace temperature distributions between FGR level and $24 \mathrm{~m}$ level above the air distributor are characterized by a similar curve shape both in the case of the FGR test and the reference test. During all performance tests on $1295 \mathrm{t} / \mathrm{h}$ supercritical CFB combustor reported in this work, bed temperature difference between air distributor level and the top of furnace chamber varied between $40 \mathrm{~K}$ and 


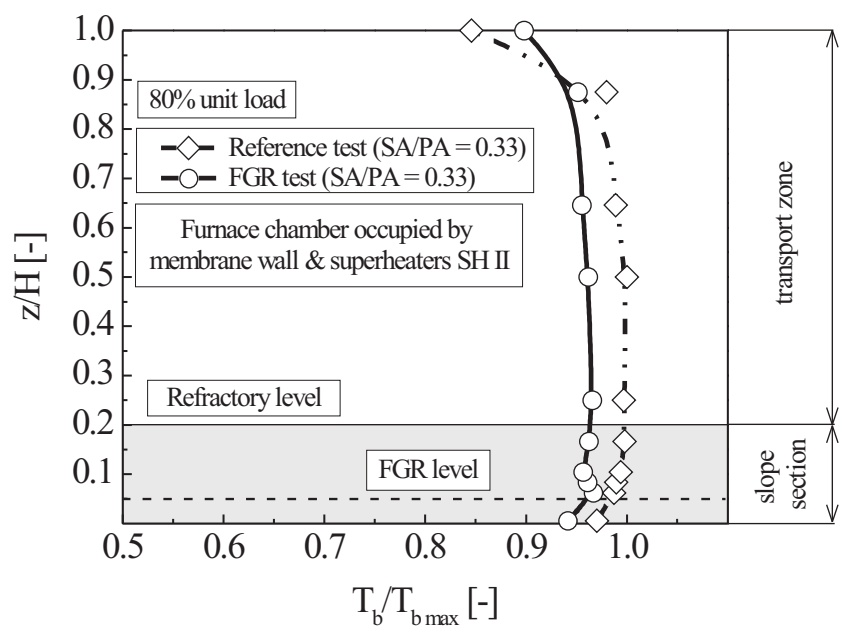

Figure 2: Vertical temperature profiles inside furnace chamber of CFB combustor.

$144 \mathrm{~K}$, for FGR test and normal operating conditions without recycled flue gases back to the furnace through star-up burners, respectively.

Figure 3 depicts the lateral temperature at the four nondimensional height coordinates above the fluidization grid for two representative conditions. When the CFB combustor was operated under normal operating conditions (i.e. without recirculation of flue gas back to furnace), the highest bed temperature in the core region was recognized at non-dimensional distance $z / H$ of 0.5 . The high bed temperature at the half CFB furnace height is caused by predominant combustion process of fuel particles in this part of furnace chamber. As it is shown, the bed temperature decreases with increasing the furnace height and also bed temperature decreases from the furnace axis to the active heat transfer surface in the transport zone of bed inventory above the refractory line. At nondimensional height coordinates $z / H$ of 0.87 , the lowest bed temperature in the core region was recognized in all cases. Furnace temperature at different elevations above the air distributor level had the same tendency, both at the FGR test and in the case of the reference test. The obtained lateral temperature profiles at different heights above the refractory line inside the furnace chamber confirm a typical core-annulus flow structure in CFB combustors. Thus, bed hydrodynamics behavior had significant impact on parabolic shape of lateral temperature profiles. Thereby the obtained lateral temperature profiles are almost axis-symmetric. In the experiments, the lowest variation on 

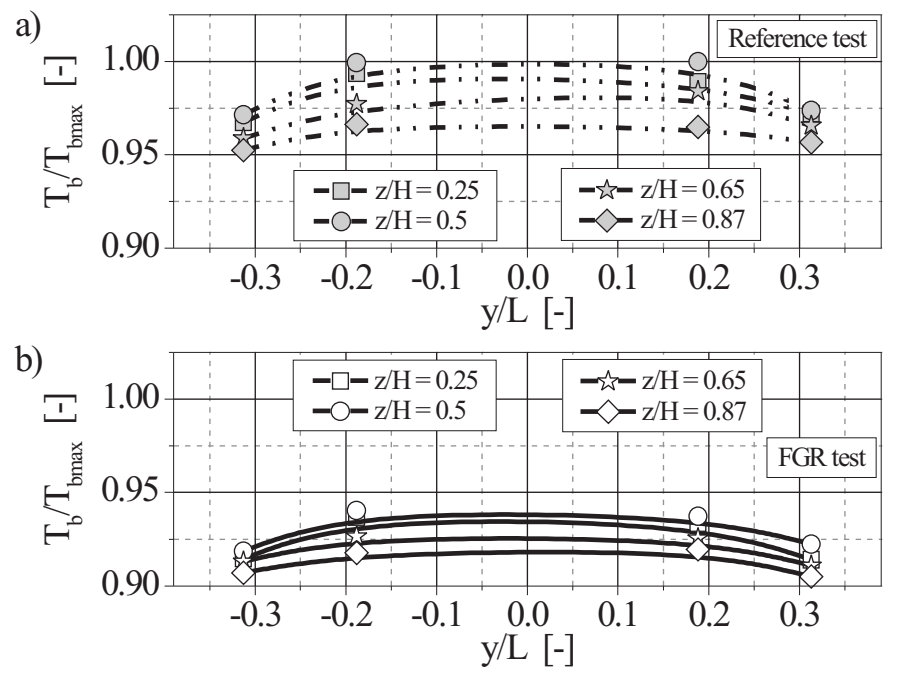

Figure 3: Lateral temperature profiles inside furnace chamber of $1296 \mathrm{t} / \mathrm{h}$ supercritical CFB combustor: a) reference test, b) FGR test.

bed temperature versus the lateral direction between the four sets of curves is recognized at FGR test. This fact indicates lower suspension density at FGR test than in the case of the reference test. Moreover, low variation on bed temperature at FGR test arises from the most rapidly transport of bed particles between annulus and core region. These conclusions are consistent with the comments in relation to the Fig.4.

The variations of suspension density along furnace height are presented in Fig. 4. The experimental data points of suspension density are drawn as individual marks for each test. The average cross-section suspension density was estimated using the following relationship:

$$
\rho_{b}=9.81^{-1}\left(P_{i}-P_{i+1}\right)\left(H_{i}+H_{i+1}\right),
$$

where $H_{i}$ and $H_{i+1}$ denote the measurement positions closest to the upper and lower end of the wall, respectively, and $P_{i}$ and $P_{i+1}$ are the corresponding pressures. Solids acceleration and the effects of gas-wall and solid-wall fraction were neglected in the Eq. (14). Transport zone defined in this study was the part of the combustion chamber between $10 \mathrm{~m}$ and $48 \mathrm{~m}$ above air distributor level. As shown in Fig. 4, the suspension density in the CFB furnace varied between $1.93 \mathrm{~kg} / \mathrm{m}^{3}$ at the $z / H=0.87$ and $1200 \mathrm{~kg} / \mathrm{m}^{3}$ at fluidization grid during all performance tests. The high suspension density at the bottom zone is due to the effect of feeding materials (i.e., fuel, sor- 
bent, circulating material) in that region of the furnace chamber. There is a difference in the axial profile of solid suspension density between the FGR test and the reference test, when the relative height is in the range of 0.05 to 0.25 . Suspension density profile above the refractory line in the upper region of CFB furnace (i.e., transport zone at $z / H>0.25$ ), both the FGR test and the reference test, are kept unchanged.

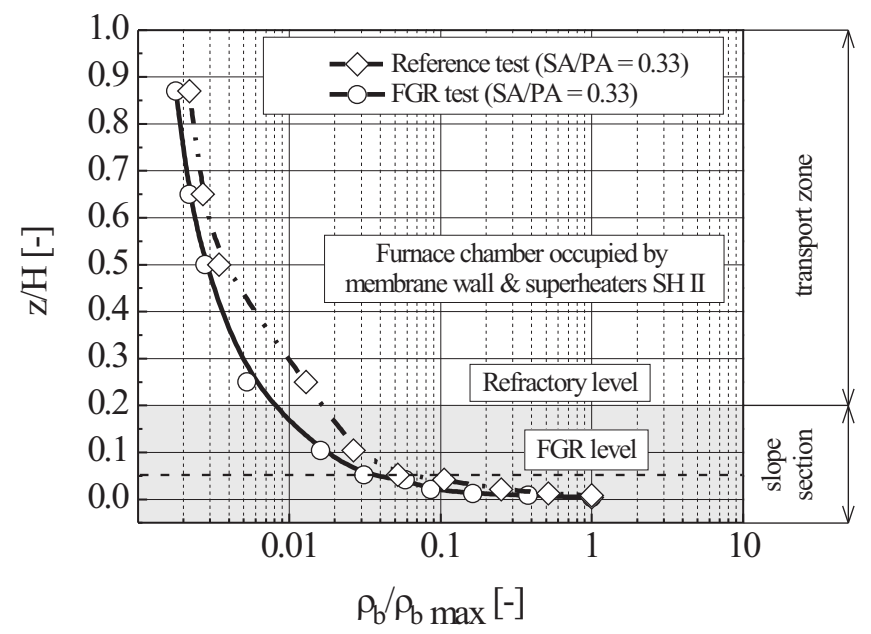

Figure 4: Solid suspension density profiles inside furnace chamber of $1296 \mathrm{t} / \mathrm{h}$ supercritical CFB combustor.

This discrepancy can be explained by the dominant effect of fluidizing gas density to accelerate in this region, where the difference between bed material and gas velocities is high. This situation was caused by the fact that different hydrodynamic conditions occurred in this region of the combustion chamber during all performance tests. On the other hand, the suspension density profiles confirmed that solids transport occurs without a splash zone as the boundary between a dense bed and dilute phase with low bed particle concentration. Besides, suspension density varied with the bed particle size and solid circulation flux. Thus, it indicates that operating conditions of CFB combustor had an essential impact on axial suspension density profile. That dependence was also confirmed by other authors [31-34].

Figure 5 shows the variation of bed-to-wall heat transfer coefficient at different tests and furnace heights. The overall heat transfer coefficient on the active heat transfer surfaces decreases gradually with distance from the refractory line during all performance tests. The obtained value of heat 
transfer coefficient were in the range from 110 to $241 \mathrm{~W} /\left(\mathrm{m}^{2} \mathrm{~K}\right)$. The variation of the heat transfer coefficient is relatively smaller for the reference test rather than under flue gas recirculation conditions. The reason for this situation is due to the dominant effect of radiative heat transfer on the wall and the furnace temperature during the reference test. The coefficient $h$ in $\mathrm{W} /\left(\mathrm{m}^{2} \mathrm{~K}\right)$, approached maximum and minimum values, when the CFB unit was operated at flue gas recirculation into the combustion chamber. In this work, overall heat transfer coefficient data show almost a linear decline. The maximum decline in heat transfer is indicated in the data at FGR test, namely, from $241 \mathrm{~W} /\left(\mathrm{m}^{2} \mathrm{~K}\right)$ to $109 \mathrm{~W} /\left(\mathrm{m}^{2} \mathrm{~K}\right)$. The behavior of bed-to-wall heat transfer coefficient arises from local fractions of the walls covered by clusters. At $z / H=0.25$, water membrane wall is covered by more clusters (about $f=49 \%$ ) than in the exit region at $z / H=0.87$ where active heat transfer surface (i.e., membrane wall and superheater SH II) are covered only a few clusters $(f=11 \%)$. Moreover, horizontal transport of bed particles between the core and annulus region can enhance the heat transfer process. This parameter depends upon the gas-solid motion in the vicinity of the heat transfer surfaces.

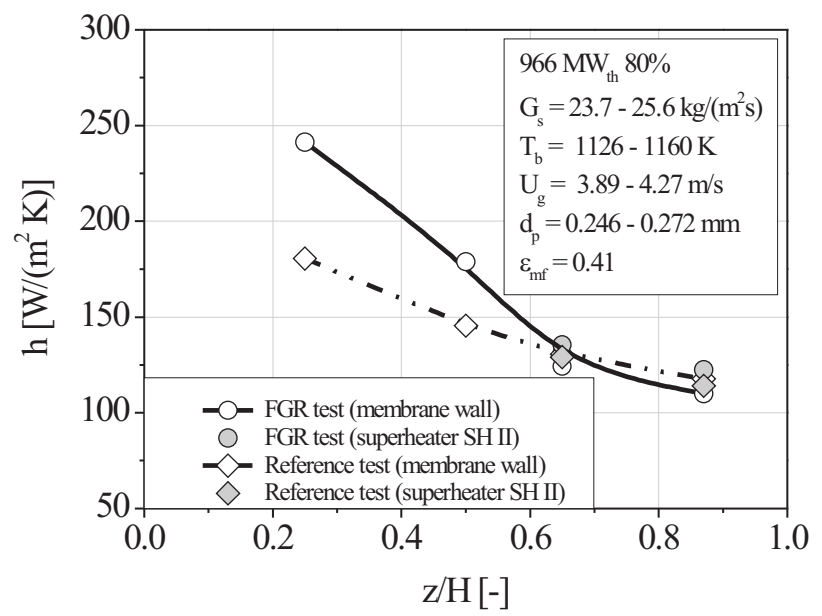

Figure 5: Bed-to-wall heat transfer coefficient versus relative height of furnace chamber.

During performance tests, the highest bed-to-wall heat transfer coefficient $241 \mathrm{~W} /\left(\mathrm{m}^{2} \mathrm{~K}\right)$ approaches when CFB combustor was operated at recycled flue gas back to the furnace. The reason for this fact is due to high carbon dioxide concentration in comparison with the reference test. At the exit region of combustion chamber, the bed-to-wall heat transfer coefficient 
reaches a minimum value of $109 \mathrm{~W} /\left(\mathrm{m}^{2} \mathrm{~K}\right)$ and $117 \mathrm{~W} /\left(\mathrm{m}^{2} \mathrm{~K}\right)$, for FGR test and reference test, respectively. As can be seen in Fig. 5, heat transfer data depends on operating conditions of CFB combustor (the interplay of the superficial gas velocity, temperature furnace and bed particle size).

Figure 6 represents the contribution of heat transfer components variation with the furnace height of supercritical CFB combustor. The variation of particle and gas convection is plotted by a black straight line and a dashed black line, respectively. Besides, the radiation heat transfer components in the overall heat transfer coefficient are shown in Fig. 6, as a grey line type of dash dot dot pattern for the cluster phase and a grey dotted line for the dispersed phase. The contributions of particle convection, $h_{p} / h$, gas convection, $h_{g} / h$, radiation from the cluster phase, $h_{r c} / h$, and radiation from the dispersed phase, $h_{r d} / h$, in the bed-to-wall heat transfer coefficient are generated based on the experimental conditions (Tab. 1) reported in the previous Section 3.

During all tests, the average contribution of convection and radiation heat transfer components varied between $15 \%-52 \%$ and $48 \%-85 \%$, respectively. In the current heat transfer study, the gas convection contribution was not significant in the bed-to-wall heat transfer as demonstrated by Fig. 6. During all performance tests, the contributions of gas convection, $h_{g} / h$, varied between $0.04 \%$ and $0.05 \%$ and can be negligible. This is due to fact that near the active heat transfer surfaces, the cluster and bed particles concentrations are so high. The same trend was also observed in [35]. Under normal operating conditions of CFB combustor (i.e., without flue gas recirculation into furnace), radiation components predominate and the contribution of particle convection being minimum in a transport zone of the furnace chamber. This is due to the fact that near the active heat transfer surfaces, both the particle and the cluster concentration decrease with an increase in the furnace height. However, for the FGR test the convection component in heat transfer to the wall prevails until to $19 \mathrm{~m}$ (i.e., $z / H=0.4$ ) distance above the air distributor. At the FGR test, the contribution of particle heat transfer coefficient for membrane wall varied between $60 \%$ at $z / H=0.25$ and $15 \%$ at $z / H=0.87$. This is caused by a longer cluster residence time and also by higher fraction of the wall covered by clusters compared with the reference test. This work confirms the strong dependency of bed-to-wall heat transfer coefficient on nondimensional distance from the fluidization grid and thereby on suspension density. There is the same tendency in contributions of heat transfer mechanisms between 

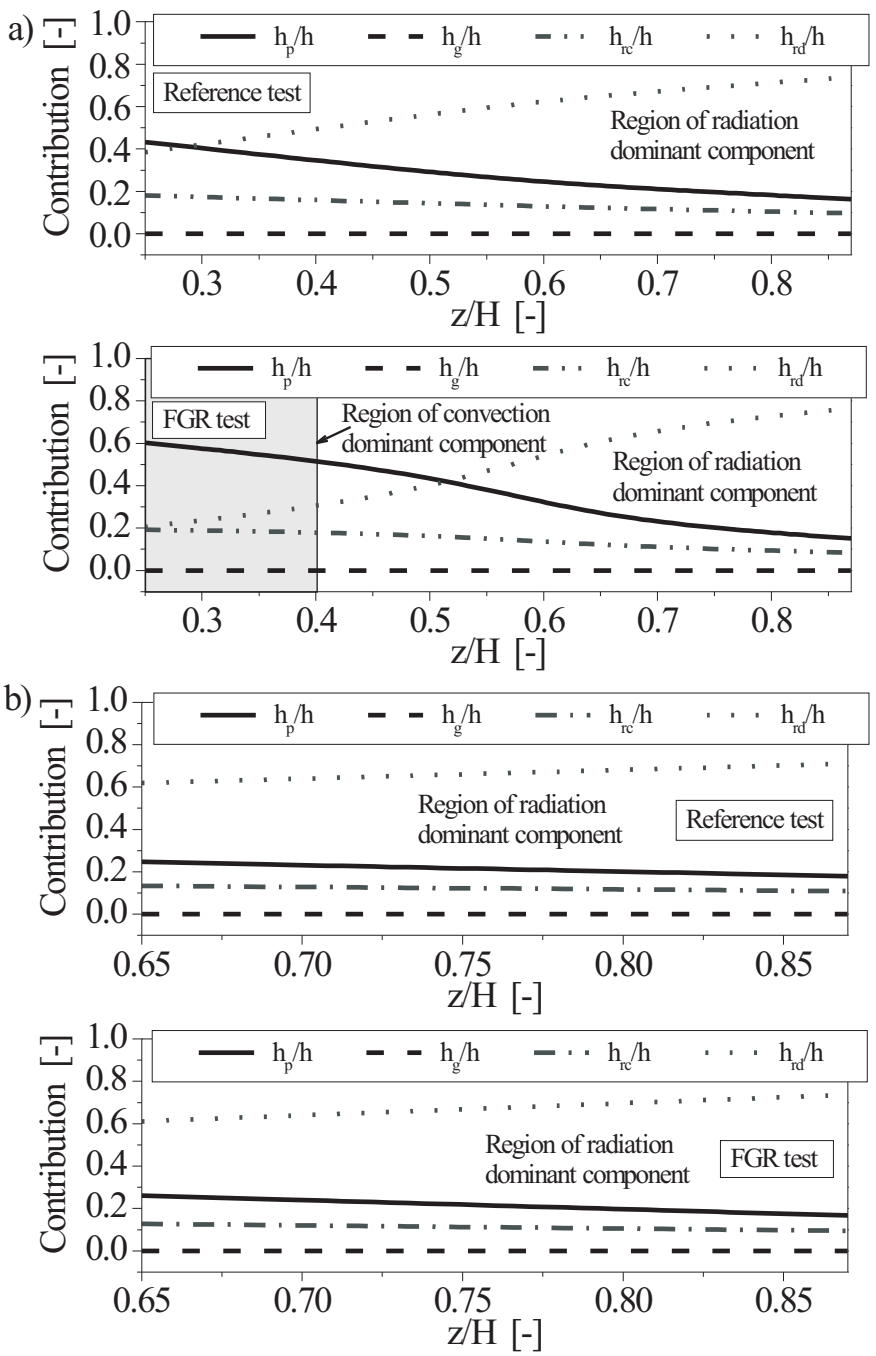

Figure 6: Contribution of components in overall heat transfer coefficient along furnace height: a) membrane wall, b) superheater SH II. 


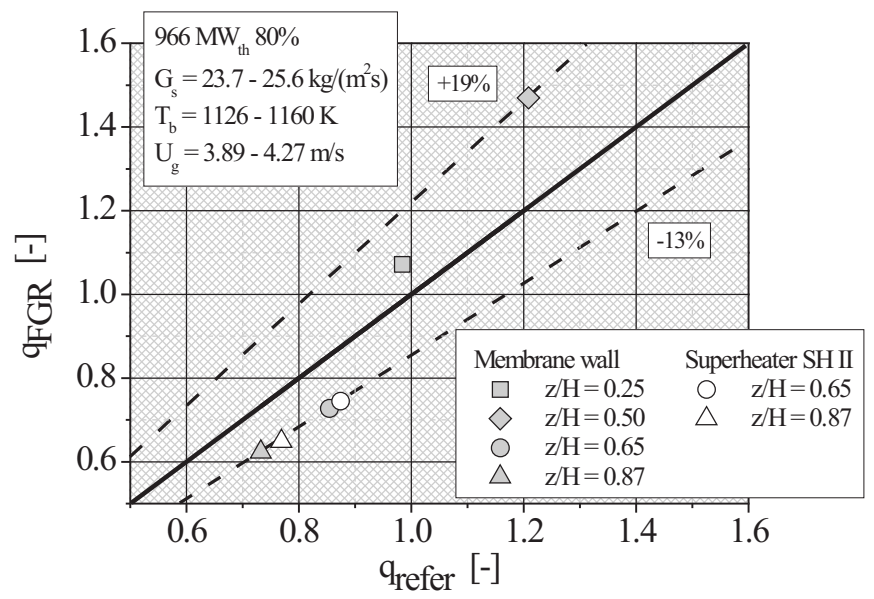

Figure 7: Comparison of relative heat flux between the FGR test and the reference test.

FGR test and reference test for superheater SH II. This can be explained by the fact that there is not significant difference in suspension density values in the exit region of furnace chamber between two representative conditions. A similar trend of the heat transfer components variation along the furnace height was observed by Basu [36] at 70\% load condition.

In the present study, heat flux recovery along the furnace height is compared between FGR test and the reference test. The heat flus recovery was calculated using the following empirical correlation:

$$
q_{i}=h_{i}\left(T_{b}-T_{w}\right), \quad i \equiv F G R, \text { refer },
$$

where $q$ denotes heat flux recovery in $\mathrm{W} / \mathrm{m}^{2}, h$ means overall heat transfer coefficient in $\mathrm{W} /\left(\mathrm{m}^{2} \mathrm{~K}\right), T_{b}$ represents bed temperature in $\mathrm{K}$ and $T_{w}$ is wall temperature of active heat transfer surface in K. The subscripts $F G R$ and refer signify the value for the flue gas recirculation test and the value for normal operating conditions of CFB combustor, respectively.

Figure 7 compares relative heat flux recovery along the furnace height between the FGR test and the reference test, for the membrane wall and the superheater SH II, respectively. All experimental data points shown in Fig. 7 are referred to the value of the heat flux recovery from the core region towards active heat transfer surfaces equal to $50 \mathrm{~kW} / \mathrm{m}^{2}$. In this work, the presentation form of the obtained values of heat flux recovery is due to commercial reason. The relative heat flux recovery increases with 
an increase in $\mathrm{CO}_{2}$ volumetric concentration due to increased nonluminous radiation from carbon dioxide inside $\mathrm{CFB}$ furnace. Moreover, the increase in gas emissivity is due to rising of the partial pressure of $\mathrm{CO}_{2}$. Therefore, the heat flux obtained for FGR test directly above the refractory line was higher about $19 \%$ than the value of the heat flux at the reference test. The above result confirms also the effect of combustion products on heat transfer. On the other hand, the heat flux recovery by membrane-wall and superheater SH II in the transport zone of furnace chamber at the FGR test was lower by about $13 \%$ than in the case of the reference test.

\section{Summary}

In a large-scale supercritical circulating fluidized bed combustor, the effect of flue gas recirculation on heat transfer behavior was investigated. Experimental data points indicate that the recycled flue gas back to furnace chamber through star-up burners affected curve shape of bed temperature. Registered furnace temperature was in the range of typical temperature for CFB boilers. During all tests, the vertical temperature profile had nonlinear character. The lowest temperature difference within combustion chamber was observed at FGR test $(\Delta T=40 \mathrm{~K})$. Thanks to the flue gas recirculation into combustion chamber almost equalized horizontal furnace temperature profiles were achieved. The axial suspension density distributions show the L-shape profile along the furnace height. The shape of suspension density profile reported in Fig. 4 resulted from the ratio of secondary to primary air, $S A / P A$. Below the secondary air injection levels, there is an exponential decay of the suspension density. On the other hand, the suspension density profile confirmed that above the secondary air injection levels bed inventory transport occurs without a splash zone as the boundary between dense bed and dilute phase. The bed-to-wall heat transfer between the active heat transfer surface and the bed includes contributions from particle and gas convection, gas conduction as well as radiation. The estimation of heat transfer characteristics was carried out on the basis of the cluster renewal approach and the experimental data from $\mathrm{CFB}$ combustor in a large-scale. The calculated overall heat transfer coefficient decreases with the relative furnace height. The highest variation of the bed-to-wall heat transfer coefficient $132 \mathrm{~W} /\left(\mathrm{m}^{2} \mathrm{~K}\right)$ approaches when CFB combustor was operated at FGR test. In the current heat transfer study, the bed-to-wall heat transfer coefficient was in the range of $109-241 \mathrm{~W} /\left(\mathrm{m}^{2} \mathrm{~K}\right)$ in the $1296 \mathrm{t} / \mathrm{h}$ supercrit- 
ical CFB combustor. The overall heat transfer coefficient depended upon hydrodynamic conditions and the flue gas recirculation rate. The obtained results indicate that the suspension density, the furnace temperature and the volumetric concentration of $\mathrm{CO}_{2}$ affected the heat transfer coefficient and also the contribution of components in heat transfer mechanism to the walls of heat exchangers. When the supercritical CFB combustor was operated with recycled flue gases back to the furnace, the convection is important mode of bed-to-wall heat transfer coefficient at the nondimensional height coordinate in the range of 0.25-0.4. Moreover, the flue gas recirculation affected shape of profile for particle convection. In all tests, the gas convection contribution to the bed-to-wall heat transfer coefficient is very low $\left(h_{g} / h<0.05 \%\right)$. The contribution of particle convection to the heat transfer mechanism along the furnace height was ranged from $15 \%$ to $60 \%$ during FGR test. The dispersed phase radiation component in the bed-towall heat transfer coefficient is dominant above nondimensional distance of 0.4 and 0.65 , for the FGR test and the normal operating conditions without recycle flue gas back to the furnace, respectively. This is due to low suspension density $\left(\rho_{b}<2.2 \mathrm{~kg} / \mathrm{m}^{3}\right)$. The variation of the cluster radiation component in the bed-to-wall heat transfer coefficient along the furnace height not depended upon the flue gas recirculation. In this work, the average contribution of radiative heat transfer components covering in range of $48 \%-85 \%$. The experimental results suggest that heat flux is substantially increased with increasing the $\mathrm{CO}_{2}$ concentration within combustion chamber. The effect of flue gas recirculation on the heat flux recovery had significant impact, especially in the case of half CFB furnace height. This is due to the impact of combustion process products. At nondimensional distance $z / H$ of 0.5 , the heat flux at FGR test was about $19 \%$ higher than in the case of the reference test for the same furnace height coordinate. In the case of flue gas recirculation test, the heat flux recovery from the core region to the walls of heat exchangers was about $13 \%$ lower than the obtained values of heat flux at relative furnace height in the range of 0.650.87 for reference conditions. The information about heat transfer data in a large-scale CFB combustor allow the development of better correlation for design and scale-up heat transfer surfaces in contact with the fluidized bed.

Acknowledgments The author would like to gratefully acknowledge the staff of Tauron Generation S.A. Lagisza Power Plant for technical support with supplying operating data. This work was financially supported by scientific research No BS-PB-406/301/11. 


\section{References}

[1] Koornneef J., Junginger M., FaAji A.: Development of fluidized bed combustion - An overview of trends, performance and cost. Prog. Energ. Combust. 33(2007), 19-55.

[2] Нотта A.: Foster Wheeler's solutions for large scale CFB boiler technology: Features and operational performance of Eagisza 460MWe CFB boiler. In: Proc. 20th Int. Conf. on Fluidized Bed Combustion, 2010, 59-70.

[3] Oka S.N.: Fluidized bed combustion. Marcel Dekker Inc., New York 2004, 1-37.

[4] REH L.: Development potentials and research needs in circulating fluidized bed combustion. China Particuology 1(2003), 5, 185-200.

[5] Tan Y., Croiset E., Douglas M.A., Thambimuthu K.V.: Combustion characteristic of coal in a mixture of oxygen and recycled flue gas. Fuel 85(2006), 507-512.

[6] Becher V., Bohn J.P., Goanta A., Spliethoff H.: A combustion concept for oxyfuel processes with low recirculation rate - Experimental validation. Combust. Flame 158(2011), 1542-1552.

[7] Li J., Zhang X., Yang W., Blasiak W.: Effects of flue gas recirculation on NOx and SOx emissions in a co-firing boiler. IJCCE 2(2013), 13-21.

[8] Blume M., Bohn J.P., Goanta A., Spielthoff H.: Reduction of the flue gas recirculation rate in oxycoal processes by means of non-stoichiometric burner operation. Energy 45(2012), 117-124.

[9] BŁaszczuk A., Nowak W., Jagodzik Sz.: Effects of operating conditions on deNOx efficiency in supercritical circulating fluidized bed boiler. J. Power Technol. 93(2013), 1, 1-8.

[10] Basu P.: Circulating fluidized bed boilers, Design, Operation and Maintenance. Springer Cham Heidelberg, New York 2015.

[11] Khartchenko N.V., Khartchenko V.M.: Advanced energy systems, 2nd Edn., CRC Press, Taylorand Francis Group, Boca Raton 2014.

[12] Dobrzański J., Zieliński A., Pasternak J., Hernas A.: Doświadczenia z zastosowania nowych stali do wytwarzania elementów kotłów na parametry nadkrytyczne. Prace Instytutu Metalurgii Żelaza 1(2010), 51-60 (in Polish).

[13] Spielthoff H.: Power generation from solid fuels. Springer, Berlin Heidelberg 2010.

[14] Chinsuman A., Dutta A.: An experimental investigation of the effect of longitudinal fin orientation on heat transfer in membrane water wall tubes in a circulating fluidized bed. Int. J. Heat Mass Tran. 52(2009), 1552-1560.

[15] Basu P., Cheng L.: An experimental and theoretical investigation into the heat transfer of a finned water wall tube in a circulating fluidized bed boiler. Int. J. Energ. Res. 24(2000), 291-308. 
[16] Luan W., Bowen B.D., Lim C.J., Brereton C.M.H., Grace J.R.: Suspension-to membrane-wall heat transfer in a circulating fluidized bed combustor. Int. J. Heat Mass Tran. 43(2000), 1173-1185.

[17] Lockhart C., Zhu J., Brereton C.M.H., Lim C.J., Grace J.R.: Local heat transfer, solids concentration and erosion around membrane tubes in a cold model circulating fluidized bed. Int. J. Heat Mass Tran. 38(1995), 2403-2410.

[18] Nag P.K., Nawsher M., Basu P.: A mathematical model for the predicted of heat transfer from finned surfaces in a circulating fluidized bed. Int. J. Heat Mass Tran. 38(1995), 1675-1681.

[19] Wu R.L., Grace J.R., Lim C.J.: A model for heat transfer in circulating fluidized beds. Chem. Eng. Sci. 45(1990), 12, 3389-3398.

[20] Noymer P.D., Glicksman L.R.: Descent velocities of particle clusters at the wall of a circulating fluidized bed. Chem. Eng. Sci. 55(2000), 5283-5289.

[21] Dutta A., BAsu P.: An improved cluster-renewal model for estimation of heat transfer coefficient on the water-walls of commercial circulating fluidized bed boilers. J. Heat Trans. 126(2004), 1040-1043.

[22] Blaszczuk A., Nowak W.: Heat transfer behavior inside a furnace chamber of large-scale supercritical CFB reactor. Int. J. Heat Mass Tran. 87(2015), 464-480.

[23] Blaszczuk A., Nowak W.: Bed-to-wall heat transfer coefficient in a supercritical CFB boiler at different bed particle size. Int J. Heat Mass Tran. 79(2014), 736-749.

[24] Basu P., Cheng L.: Heat transfer in a pressurized circulating fluidized bed. Int. J. Heat Mass Tran. 39(1996), 13, 2711-2722.

[25] BŁaszczuk A., Nowak W., Jagodzik Sz.: The impact of bed particle size in heat transfer to membrane walls of supercritical CFB boiler. Arch. Thermodyn. 35(2014), 3, 207-223.

[26] Grace J.R.: Fluidized bed heat transfer, in: G. Hestroni (Ed.), Handbook of Multiphase Flow, McGraw-Hill, Hemisphere, Washington, DC, 1982, 9-70.

[27] BŁaszczuk A., Nowak W., Jagodzik Sz.: Bed-to-wall heat transfer in a supercritical circulating fluidised bed boiler. Chem. Process Eng. 35(2014), 2, 191-204.

[28] Brewster M.Q.: Effective absorptivity and emissivity of particulate media with application to fluidized bed. Trans. ASME J. Heat Transfer 108(1986), 710-713.

[29] Blaszczuk A, Zylka A., Leszczynski J.: Simulation of mass balance behavior in a large-scale circulating fluidized bed reactor. Particuology (2015), http://dx.doi.org/10.1016/j.partic.2015.04.003 (in press).

[30] Origin 8 User Guide. OriginLab Corporation, 2007.

[31] Andersson B.A.: Effects of bed particle size on heat transfer in circulating fluidized bed boilers. Powder Technol. 87(1996), 239-248.

[32] Patil R.S., Pandey M., Mahanta P.: Parametric studies and effect of scale-up on wall-to-bed heat transfer characteristic of circulating fluidized bed risers. Exp. Therm. Fluid Sci. 35(2011), 485-494.

[33] Kolar A.K., Sundaresan R.: Heat transfer characteristic at an axial tube in a circulating fluidized bed riser. Int. J. Therm. Sci. 41(2002), 673-681. 
[34] MA Y., Zhu J.-X.: Heat transfer between gas-solids suspension and immersed surface in an upflow fluidized bed (riser). Chem. Eng. Sci. 55(2000), 981-989.

[35] RedDy B.V.: Fundamental heat transfer mechanism between bed-to membrane water-walls in circulating fluidized bed combustors. Int. J. Energy Res. 27(2003), 813-824.

[36] BAsu P.: Combustion and gasification in fluidized beds. CRC Press Taylor and Francis Group, Boca Raton, 2006. 